\title{
Changes in Pulmonary Vascular Tone during Exercise Effects of Nitric Oxide (NO) Synthase Inhibition, L-Arginine Infusion, and NO Inhalation
}

\author{
Tomonobu Koizumi, Rishi Gupta, Mukul Banerjee, and John H. Newman \\ Vanderbilt Center for Lung Research, Department of Medicine, Vanderbilt University School of Medicine, Department of Physiology, \\ Meharry Medical College, Nashville, Tennessee 37232-2650
}

\begin{abstract}
Nitric oxide (NO) is a potent endogenous vasodilator. Its role in the normal and stressed pulmonary circulation is unclear. To better understand the importance of endogenous NO in normal physiological responses, we studied the effects of altered NO availability on the change in pulmonary vascular tone that accompanies exercise. In paired studies we measured blood flow and pressures in the pulmonary circulation at rest and during treadmill exercise at a speed of $4 \mathrm{mph}$ with and without $(a) N \omega$-nitro-L-arginine, $20 \mathrm{mg} / \mathrm{kg}$ intravenously, a selective inhibitor of NO synthase; (b) L-arginine, $200 \mathrm{mg} / \mathrm{kg}$ intravenously, substrate for NO synthase; $(c)$ combination of the inhibitor and substrate; and $(d)$ inhalation of $N O>30 \mathrm{ppm}$, to determine if endogenous release of $\mathrm{NO}$ elicits maximal vasodilation. In addition, we sought to determine the site of NO effect in the pulmonary circulation by preconstriction with either $U$ 44619 or hypoxia (fraction of inspired $O_{2}=0.12$ ) using a distal wedged pulmonary catheter technique. NO synthase inhibition raised pulmonary vascular tone equally at rest and exercise. L-Arginine reversed the effects of NO synthase inhibition but had no independent effect. NO inhalation did not reduce pulmonary vascular tone at rest or enhance the usual reduction in pulmonary vascular resistance with exercise. The effect of NO synthase inhibition was in pulmonary vessels upstream from small veins, suggesting that endogenous NO dilates primarily small arteries and veins at rest. We conclude that, in sheep, endogenous NO has a basal vasodilator function that persists during, but is not enhanced by, exercise. (J. Clin. Invest. 1994. 94:2275-2282.) Key words: nitric oxide $\cdot$ pulmonary circulation • exercise - NO synthase inhibition
\end{abstract}

\section{Introduction}

The objective of this study was to examine the role of nitric oxide $(\mathrm{NO})^{1}$ in the pulmonary circulation at rest and during

Address correspondence to John H. Newman, M.D., B1308 Vanderbilt Medical Center North, Nashville, TN 37232-2650.

Received for publication 18 February 1994 and in revised form 16 August 1994.

1. Abbreviations used in this paper: $\mathrm{CO}$, cardiac output; $\mathrm{FIO}_{2}$, fraction of inspired $\mathrm{O}_{2}$; NLA, $N \omega$-nitro-L-arginine; NO, nitric oxide; Pla, left arterial pressure; Pmw, pulmonary artery microwedge pressure; Ppa, pulmonary artery pressure; PVR, pulmonary vascular resistance.

J. Clin. Invest.

(c) The American Society for Clinical Investigation, Inc. $0021-9738 / 94 / 12 / 2275 / 08 \quad \$ 2.00$

Volume 94, December 1994, 2275-2282 exercise in adult sheep. During moderate exercise, pulmonary blood flow increases two- to fourfold, and there is a quantitatively smaller increase in pulmonary artery pressure (Ppa) (1). These changes are associated with a significant reduction in pulmonary vascular resistance (PVR) in animals $(2,3)$ and in humans (4). The mechanisms for the decrease in PVR during exercise are not completely understood (3-6).

The vascular endothelium responds to multiple physiological stimuli by releasing vasoactive mediators that regulate vascular tone. For example, changes in blood flow or shear stress can stimulate prostacyclin $(7,8)$ or NO release $(9,10)$. NO or a closely related molecule enzymatically derived from L-arginine $(9,10)$ is a potent pulmonary vasodilator and regulates pulmonary vascular tone in some species (11). Release of NO in response to increased flow across the endothelium has been demonstrated in vitro (11), and NO may contribute to the progressive rise in pulmonary blood flow at birth $(12,13)$. Basal NO release is partly responsible for the low pulmonary vascular tone at rest in adult sheep, and NO synthase inhibition in sheep results in pulmonary hypertension during exercise (6). Furthermore, exogenous inhaled NO has been shown to be a pulmonary vasodilator in experimental models and human diseases (14). The fundamental role of endogenous NO in the normal pulmonary circulation during exercise has not been clarified.

From these observations, we hypothesized that NO release may be important in the adaptation of the pulmonary vasculature to the large increase in blood flow associated with exercise. We performed experiments at rest and exercise to examine the effects of $(a)$ a selective inhibitor of NO synthase, $(b)$ NO substrate supplementation with L-arginine with and without NO synthase inhibition, and $(c)$ the effects of inhaled NO on pulmonary hemodynamics in the normal and preconstricted pulmonary circulation. Preconstriction is useful to measure vasodilator potential in the pulmonary circulation because the bed ordinarily has such low tone that vasodilation is hard to detect. Endothelial-dependent relaxation is observed in both pulmonary artery and vein in vitro $(15,16)$, but little information exists on distribution or site of the action of NO in the pulmonary vascular bed in vivo. Thus, we also examined the longitudinal distribution of PVR during NO synthase inhibition and NO inhalation using the pulmonary "microwedge" pressure to partition the pulmonary vascular bed between large and small vessels $(2,17,18)$.

\section{Methods}

Surgical preparation. Adult sheep weighing $20-35 \mathrm{~kg}$ were prepared for measurements of vascular pressure and blood flow as described previously $(1-3,5,6)$. Under general anesthesia with halothane, a left thoracotomy was performed, and the left atrium and main pulmonary artery were directly cannulated with silastic catheters. An ultrasonic flow probe (Transonic Systems, Inc., Ithaca, NY) was placed around the main pulmonary artery for continuous measurement of cardiac output 
Table I. Dose Response of NLA on Hemodynamics

\begin{tabular}{|c|c|c|c|c|c|c|c|c|c|c|}
\hline & \multicolumn{2}{|c|}{$\mathrm{NLA} 1 \mathrm{mg} / \mathrm{kg}$} & \multicolumn{2}{|c|}{ NLA $5 \mathrm{mg} / \mathrm{kg}$} & \multicolumn{2}{|c|}{ NLA $10 \mathrm{mg} / \mathrm{kg}$} & \multicolumn{2}{|c|}{ NLA $20 \mathrm{mg} / \mathrm{kg}$} & \multicolumn{2}{|c|}{ NLA $30 \mathrm{mg} / \mathrm{kg}^{\ddagger}$} \\
\hline & $\mathrm{BL}$ & Drug & $\mathrm{BL}$ & Drug & BL & Drug & BL & Drug & BL & Drug \\
\hline Ppa & $19.0 \pm 0.8$ & $20.5 \pm 1.3$ & $20.0 \pm 1.3$ & $25.2 \pm 1.8^{*}$ & $17.1 \pm 0.9$ & $22.7 \pm 1.6^{*}$ & $17.8 \pm 1.3$ & $30.2 \pm 2.5^{*}$ & $18.2 \pm 1.6$ & $34.8 \pm 3.0^{*}$ \\
\hline Pla & $1.2 \pm 0.9$ & $1.3 \pm 0.8$ & $1.3 \pm 0.8$ & $1.6 \pm 1.2$ & $0.5 \pm 0.7$ & $0.9 \pm 1.2$ & $1.3 \pm 0.4$ & $2.9 \pm 1.1$ & $0.4 \pm 0.7$ & $0.8 \pm 0.8$ \\
\hline $\mathrm{CO}$ & $3.82 \pm 0.22$ & $3.42 \pm 0.27 *$ & $4.09 \pm 0.15$ & $3.44 \pm 0.21 *$ & $3.62 \pm 0.28$ & $2.72 \pm 0.25 *$ & $3.56 \pm 0.31$ & $2.69 \pm 0.26^{*}$ & $3.66 \pm 0.35$ & $2.75 \pm 0.19 *$ \\
\hline PVR & $4.72 \pm 0.38$ & $5.80 \pm 0.72$ & $4.56 \pm 0.31$ & $6.89 \pm 0.71 *$ & $4.70 \pm 0.46$ & $8.29 \pm 1.18^{*}$ & $4.73 \pm 0.49$ & $10.1 \pm 0.83 *$ & $4.87 \pm 0.26$ & $12.5 \pm 0.36^{*}$ \\
\hline Psa & $88.8 \pm 5.4$ & $88.8 \pm 4.8$ & $87.0 \pm 4.4$ & $96.0 \pm 5.5^{*}$ & $87.0 \pm 5.9$ & $94.4 \pm 5.8^{*}$ & $89.7 \pm 4.5$ & $98.1 \pm 4.6^{*}$ & $80.0 \pm 3.0$ & $100 \pm 2.6^{*}$ \\
\hline HR & $92.3 \pm 3.1$ & $87.6 \pm 4.5$ & $102 \pm 6.3$ & $95.7 \pm 6.8$ & $98.2 \pm 4.7$ & $89.2 \pm 5.8$ & $106.3 \pm 5.6$ & $96.7 \pm 2.1$ & $93.5 \pm 2.1$ & $85.3 \pm 4.2$ \\
\hline
\end{tabular}

Data are means $\pm \mathrm{SE}(n=5) ;{ }^{\ddagger} n=4$. Ppa and Pla are given in $\mathrm{cmH}_{2} \mathrm{O}$; $\mathrm{CO}$ in liters per minute, $\mathrm{PVR}$ in $\mathrm{cmH}_{2} \mathrm{O}$ per liter per minute; Psa is systemic artery pressure in $\mathrm{mmHg}$; and $\mathrm{HR}$ is heart rate in beats per minute. ${ }^{*} P<0.05$ differs from baseline $(B L)$.

(CO). Through a right neck incision, a No. 8 introducer (Cordis Laboratories Inc., Miami, FL) was inserted into the jugular vein, and a silastic catheter was placed into the aorta through the carotid artery. Some animals had a permanent tracheostomy made under a second general anesthesia. After surgery, sheep were allowed to recover in pens for 4$7 \mathrm{~d}$ with free access to water and feed before the start of exercise training and experiments. For exercise, animals were fitted with a padded leather collar which was attached at a comfortable level to side posts built onto a treadmill (Quinton Instruments Co., Seattle, WA). The sheep were acclimated to the treadmill at progressive speeds over several days until they could trot at $4 \mathrm{mph}$ for over $4 \mathrm{~min}$ without discomfort.

Physiologic measurements. Hemodynamic variables were continuously recorded at rest and during exercise using pressure transducers and an electronic recorder (MT95000; Astro-Med, Inc., West Warwick, RI). The zero reference for pressures was set near the level of the left atrium. Pulmonary blood flow was measured continuously by the implanted ultrasonic flow probe which was connected to a flowmeter (Transonic Systems, Inc.), and the signal was displayed on the electronic recorder. The ultrasonic flow values were calibrated to $\mathrm{COs}$ determined by the thermodilution method using a $\mathrm{CO}$ computer (model $9520 \mathrm{~A}$; Edwards Co., Santa Ana, CA). To raise CO, isoproterenol, $5 \mathrm{mg}$ in 100 $\mathrm{ml}$ normal saline, was infused intravenously at different rates into each sheep at rest using a pump (Harvard Apparatus, Inc., South Natick, MA). Flow meter and thermodilution values were measured at multiple $\mathrm{COs}$ at steady state, and a correlation plot and regression equation were constructed for each animal $(2,3,6)$. Arterial blood gas tensions and $\mathrm{pH}$ were analyzed with a $\mathrm{pH} /$ blood gas analyzer (model 158; Corning Medical and Scientific, Medfield, MA).

Experimental protocols. In all studies, we continuously measured $\mathrm{Ppa}$, left atrial pressure, and $\mathrm{CO}$ at rest and exercise. Systemic artery pressure was measured in most protocols.

Dosing of $N \omega$-nitro-L-arginine ( $N L A)$. To determine the most useful dose of NLA (Sigma Chemical Co., St. Louis, MO), five sheep were given five doses $(1.0,5.0,10,20$, and $30 \mathrm{mg} / \mathrm{kg})$, administered on separate days in random order (Table I). After baseline measurements, NLA was given by bolus into the pulmonary artery catheter. Hemodynamic measurements were continued for at least $30 \mathrm{~min}$ after drug administration. New steady state values occurred within $15-20 \mathrm{~min}$ (Table I). NLA caused dose-dependent increases in pulmonary and systemic artery pressure. CO significantly decreased with the first dose, $1 \mathrm{mg} / \mathrm{kg}$ of NLA. Ppa rose despite the decrease in CO, denoting true vasoconstriction. The increase in PVR observed in response to increasing doses of NLA was dose dependent; $30 \mathrm{mg} / \mathrm{kg}$ of NLA caused a marked increase in PVR from $4.87 \pm 0.26$ to $12.5 \pm 0.37 \mathrm{cmH}_{2} \mathrm{O} /$ liter per minute. We chose $20 \mathrm{mg} / \mathrm{kg}$ for a standard dose of NLA because it reliably raised Ppa without causing severe systemic hypertension or large reduction in $\mathrm{CO}$. This is the dose used by most other investigators $(19,20)$

Effects of NO synthase inhibition and L-arginine on pulmonary he- modynamics during exercise. In paired studies, six sheep exercised on a treadmill at a constant speed of $4 \mathrm{mph}$ for 4 min untreated, with NLA pretreatment, or with NLA plus L-arginine (Sigma Chemical Co.) pretreatment. In the NLA-alone arm, exercise was begun 20 min after drug infusion. On a separate day, sheep were treated first with NLA for $20 \mathrm{~min}$ followed by L-arginine $(200 \mathrm{mg} / \mathrm{kg})$ by bolus via the pulmonary artery catheter. Exercise was begun $\sim 10 \mathrm{~min}$ after L-arginine infusion.

In paired studies, four sheep exercised with and without L-arginine pretreatment. Sheep received L-arginine, $200 \mathrm{mg} / \mathrm{kg}$ intravenously by bolus, via the pulmonary artery catheter after steady state baseline. Exercise was begun $\sim 10$ min after administration of L-arginine (Table II).

Effects of inhaled NO on pulmonary hemodynamics during exercise. In six trained sheep a tracheostomy was made under general anesthesia. After $2 \mathrm{~d}$ of recovery, a No. 10 Shiley tracheostomy tube was placed, and sheep were exercised with and without NO inhalation. NO gas (50 ppm in $\mathrm{N}_{2}$ ) was mixed with $\mathrm{O}_{2}$ using a Bennett 50 psi gas blender, and delivered by a high-flow regulator through low-resistance ventilator tubing and one-way valves to prevent rebreathing. The fraction of inspired $\mathrm{O}_{2}\left(\mathrm{FIO}_{2}\right)$ was set at 0.25 on the blender. The final concentration of $\mathrm{NO}$ at the mouth was $\sim 40 \mathrm{ppm}(1-0.25) \times 50 \mathrm{ppm}$. From other studies, NO gas has vasodilator effects at concentration as low as 2 ppm, and maximal effects occur at $<40 \mathrm{ppm}(14,21)$. After steady state values were observed on room air, sheep then breathed control gas $\left(\mathrm{O}_{2}=25 \%, \mathrm{~N}_{2}=75 \%\right)$ via the gas delivery system. After a new steady state was achieved while breathing control gas, sheep exercised at 4 $\mathrm{mph}$ for $4 \mathrm{~min}$. Sheep then rested for over $1 \mathrm{~h}$ and were restudied while breathing NO.

Effects of inhaled NO on hypoxia- and U46619-induced vasoconstriction during exercise. In paired studies, six sheep breathed hypoxic gas at baseline and during exercise with and without inhaled NO. Hypoxic gas was delivered via the blender at $\mathrm{FIO}_{2} 0.12$, resulting in an arterial $\mathrm{PaO}_{2}$ of $\sim 40$ Torr. After 20 min, when pulmonary hypertension was stable, sheep were exercised. In the NO inhalation part of the study, sheep breathed $\mathrm{NO}$ at an $\mathrm{FIO}_{2}$ of 0.12 after reaching a stable hypoxic pressor response and then were exercised.

Similarly, six sheep received continuous intravenous infusion of U46619 in saline at baseline and during exercise with and without NO inhalation. We used the stable 9-methylene ether analogue of $\mathrm{PGH}_{2}$ [ $(15 S)$ hydroxy-11 $\alpha, 9 \alpha$-(epoxymethano) prosta-5Z, 13-dienoic acid; The Upjohn Co., Kalamazoo, MI]. U46619 was continuously infused into sheep at $4-10 \mu \mathrm{g} / \mathrm{min}$ to produce at least a $50 \%$ increase in Ppa. After reaching stable effects of U46619, sheep were exercised. In the NO inhalation part of this protocol, sheep breathed NO after the pressor response to U46619 was stable and were then exercised.

Distribution of PVR during NLA infusion, hypoxia, and U46619. In six sheep, we measured Ppa, pulmonary artery microwedge pressure (Pmw), left arterial pressure (Pla), and CO continuously to assess the longitudinal distribution of pulmonary resistance. To obtain Pmw, a 
Table II. Effect of NO Substrate (L-Arginine) on Hemodynamics

\begin{tabular}{|c|c|c|c|c|c|c|}
\hline & \multicolumn{2}{|c|}{ Rest } & \multicolumn{4}{|c|}{ Exercise $(s)$} \\
\hline & BL & Post-treatment & 20 & 60 & 120 & 240 \\
\hline \multicolumn{7}{|l|}{ Ppa } \\
\hline Control & $19.5 \pm 2.0$ & $19.5 \pm 2.0$ & $28.6 \pm 1.8^{*}$ & $28.6 \pm 1.7^{*}$ & $27.4 \pm 2.0$ & $25.8 \pm 2.4$ \\
\hline L-Arginine & $17.8 \pm 1.3$ & $19.0 \pm 0.9$ & $28.3 \pm 2.0^{*}$ & $28.8 \pm 2.7^{*}$ & $27.5 \pm 3.4$ & $26.3 \pm 2.5$ \\
\hline \multicolumn{7}{|l|}{$\mathrm{Pla}$} \\
\hline Control & $0.8 \pm 0.5$ & $1.1 \pm 0.2$ & $4.8 \pm 1.3 *$ & $4.0 \pm 1.3$ & $2.5 \pm 0.9$ & $2.1 \pm 0.9$ \\
\hline L-Arginine & $0.8 \pm 0.1$ & $0.6 \pm 0.3$ & $4.5 \pm 0.8 *$ & $3.7 \pm 1.1$ & $3.4 \pm 1.2$ & $1.8 \pm 0.8$ \\
\hline \multicolumn{7}{|l|}{$\mathrm{CO}$} \\
\hline Control & $4.3 \pm 0.4$ & $4.3 \pm 0.4$ & $6.8 \pm 1.0 *$ & $8.4 \pm 0.9 *$ & $8.5 \pm 0.8^{*}$ & $8.7 \pm 0.9 *$ \\
\hline L-Arginine & $4.2 \pm 0.3$ & $4.8 \pm 0.2$ & $7.9 \pm 0.7 *$ & $9.1 \pm 0.7 *$ & $9.1 \pm 0.7 *$ & $8.9 \pm 0.6 *$ \\
\hline \multicolumn{7}{|l|}{ PVR } \\
\hline Control & $4.6 \pm 0.3$ & $4.4 \pm 0.3$ & $3.7 \pm 0.2$ & $3.1 \pm 0.2^{*}$ & $3.0 \pm 0.2 *$ & $2.7 \pm 0.1 *$ \\
\hline L-Arginine & $4.2 \pm 0.2$ & $3.8 \pm 0.1$ & $3.2 \pm 0.1$ & $2.8 \pm 0.1 *$ & $2.6 \pm 0.1 *$ & $2.7 \pm 0.1^{*}$ \\
\hline
\end{tabular}

* $P<0.05$ versus baseline and post-treatment. Pulmonary hemodynamics at rest and during exercise at 4 mph in control and L-arginine-pretreated sheep ( $n=4$, paired). $B L$, baseline. Ppa and Pla are given in $\mathrm{cmH}_{2} \mathrm{O}$; and $\mathrm{CO}$ is given in liters per minute. Values are means \pm SE.

No. 7 Swan-Ganz catheter (Edwards Co.) was advanced through the introducer (Cordis Laboratories Inc.) into the pulmonary artery to an initial wedge position guided by the vascular pressure tracing. The catheter was then readvanced with the balloon deflated into a more distal wedge position. The criteria for attainment of Pmw are described in detail in previous studies $(2,6)$. Total PVR $=(\mathrm{Ppa}-\mathrm{Pla}) / \mathrm{CO}$; upstream resistance $(\mathrm{PVRup})=(\mathrm{Ppa}-\mathrm{Pmw}) / \mathrm{CO}$; downstream resistance $($ PVRdown $)=($ Pmw - Pla $) / C O$. NLA $(20 \mathrm{mg} / \mathrm{kg})$ was infused via the pulmonary artery catheter, and then the sheep were exercised. Similarly, hypoxic gas and U46619 were given as described above. After new steady state hemodynamic responses were observed, NO was started. Pulmonary vascular segment resistances were calculated.

Statistics. Data are expressed as means \pm SE. Data were analyzed by one- and two-way ANOVA, using Number Cruncher Statistical System (Kaysville, UT). Tests for differences in groups and between baseline and experimental values were by Duncan's new multiple range test. Paired $t$ test was used for within group comparisons for a single variable. Significant differences were assumed at $P<0.05$. To compare changes in exercise-induced pulmonary vasodilation we calculated percent change in PVR as (PVRexp - PVRrest)/PVR rest $\times 100$.

\section{Results}

Effects of NLA on pulmonary hemodynamics during exercise. Hemodynamic values at rest and during exercise in control, NLA-treated, and NLA + L-arginine-treated sheep are summarized in Figs. 1 and 2. In control runs, Ppa rose from 21.3 \pm 1.5 at baseline to a peak of $34.2 \pm 3.8 \mathrm{cmH}_{2} \mathrm{O}$ within $60 \mathrm{~s}$ of exercise, then decreased to $30.9 \pm 4.6 \mathrm{cmH}_{2} \mathrm{O}$ at $240 \mathrm{~s}$. $\mathrm{CO}$ rose precipitously at the start of exercise, to a level double that of baseline, and then remained stable. Changes in Pla during control exercise were small; Pmw rose slightly from $7.9 \pm 0.9$ at baseline to a peak of $11.2 \pm 1.1 \mathrm{cmH}_{2} \mathrm{O}$ at $40 \mathrm{~s}$ of exercise $(P=\mathrm{NS})$ and then gradually decreased. PVR decreased abruptly with exercise from $4.87 \pm 0.56$ to $3.78 \pm 0.44 \mathrm{cmH}_{2} \mathrm{O} /$ liter per minute at $20 \mathrm{~s}$ and then more gradually to a nadir of $3.00 \pm 0.18 \mathrm{cmH}_{2} \mathrm{O} /$ liter per minute at $4 \mathrm{~min}$ of exercise.

NLA $(20 \mathrm{mg} / \mathrm{kg})$ treatment caused an increase in Ppa at rest from $21.7 \pm 1.4$ to $35.2 \pm 4.7 \mathrm{cmH}_{2} \mathrm{O}(P<0.05)$, a decrease in CO from $4.6 \pm 0.44$ to $3.5 \pm 0.29$ liters $/ \mathrm{min}(P<0.05)$, and a rise in PVR from 5.1 \pm 0.5 to $9.8 \pm 1.0 \mathrm{cmH}_{2} \mathrm{O} /$ liter per minute $(P<0.05)$. During exercise, Ppa increased to a significantly higher level than in control runs, reaching a peak of $55.3 \pm 5.7$ $\mathrm{cmH}_{2} \mathrm{O}$ at $60 \mathrm{~s}$. $\mathrm{CO}$ during exercise was significantly lower than

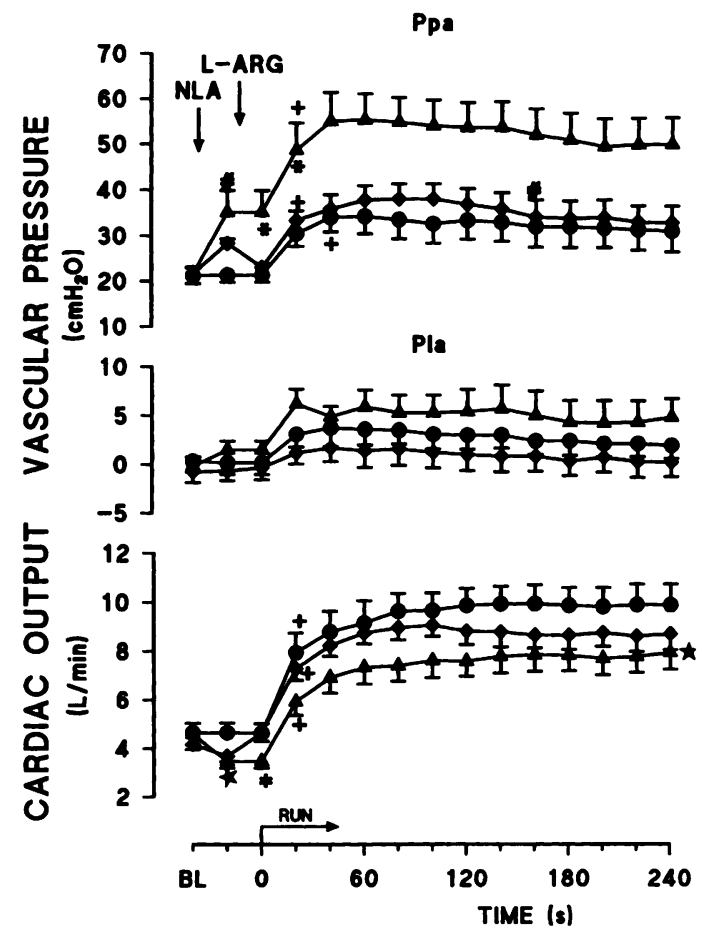

Figure 1. Pulmonary hemodynamics at rest and during exercise at 4 mph in control (filled circle), NLA-(filled triangle), and NLA + Larginine-(filled diamond) pretreated sheep $(n=6$, paired). $B L$, baseline; L-ARG, L-arginine, for this and all subsequent points. Values are means \pm SE. " $P<0.05$ for this and all subsequent points versus baseline. ${ }^{+} P<0.05$ for this and all subsequent points versus baseline and time $0 .{ }^{*} P<0.05$ for this and all subsequent points versus other groups. ${ }^{\star} P<0.05$ versus control. 


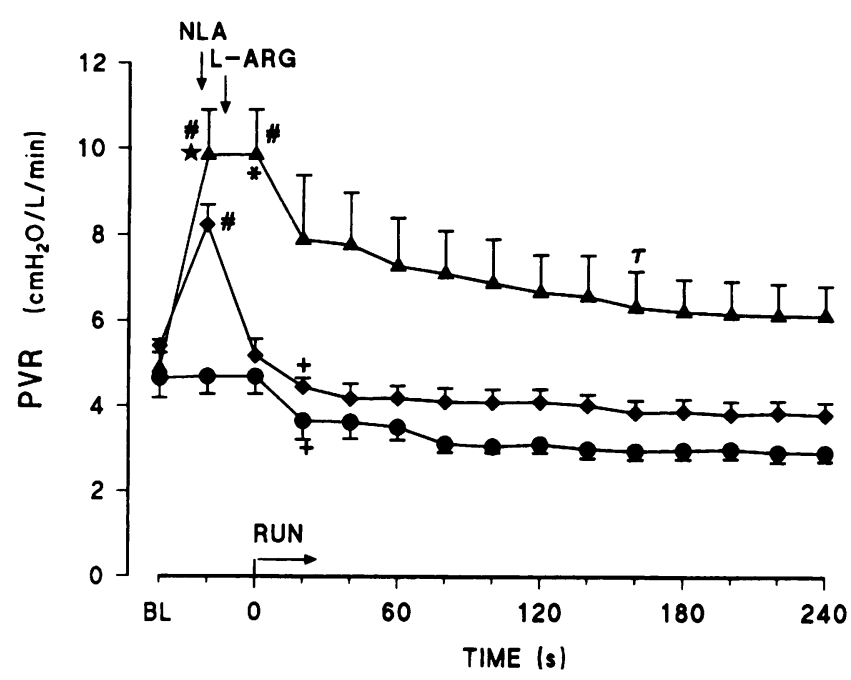

Figure 2. The changes in PVR at rest and during exercise in controls (filled circles), NLA (filled triangles) and NLA + L-arginine (filled diamonds) treatment ( $n=6$, paired). $B L$, baseline; L-ARG, L-arginine. Values are means \pm SE. ${ }^{"} P<0.05$ versus baseline. ${ }^{+} P<0.05$ for this and all subsequent points versus baseline and time $0 .{ }^{\tau} P<0.05$ for this and subsequent points versus time $0 .{ }^{*} P<0.05$ for this and all subsequent points versus other groups. ${ }^{\star} P<0.05$ versus control.

in controls. Changes in Pla and Pmw were similar to those of controls. PVR in NLA-treated sheep decreased to $7.9 \pm 1.6$ within $20 \mathrm{~s}$ of exercise and then decreased more gradually to a level of $5.9 \pm 0.8 \mathrm{cmH}_{2} \mathrm{O}$ liter per minute at $4 \mathrm{~min}$. PVR during exercise in NLA-pretreated sheep was significantly higher than in control runs (Fig. 2). However, the percent change in PVR after the onset of exercise was the same in NLA-pretreated and control sheep (Fig. 3).

In the NLA + L-arginine-treated sheep, NLA also caused a significant increase in PVR at rest from $5.4 \pm 0.1$ to $8.4 \pm 0.6$ $\mathrm{cmH}_{2} \mathrm{O} /$ liter per minute. L-Arginine administration fully reversed the NLA-induced vasoconstriction back to control levels at rest and during exercise (Fig. 2).

Systemic blood pressures at rest and exercise in control and during NLA and NLA + L-arginine treatment are shown in Table III. NLA significantly raised BP at rest. BP was no different than controls with L-arginine reversal. There were no significant changes by one-way ANOVA with exercise, although BP rose in each group, probably because of the small number of sheep.

Effects of L-arginine alone on hemodynamics. CO slightly increased after L-arginine treatment (from $4.2 \pm 0.3$ to $4.8 \pm 0.2$ $\mathrm{cmH}_{2} \mathrm{O} /$ liter per minute), but this change was not significant (Table II). The time course and magnitude of changes in Ppa, $\mathrm{Pla}, \mathrm{CO}$, and PVR during exercise were similar to those of control runs (Table II, Fig. 3 ).

Effects of NO inhalation at rest and during exercise. NO inhalation slightly reduced PVR from $4.6 \pm 0.2$ to $4.0 \pm 0.3$ at rest, due to a fall in Ppa from $18.9 \pm 0.7$ to $16.3 \pm 0.8$ $\mathrm{cmH}_{2} \mathrm{O}$, although the change did not reach statistical significance (Table IV). Inhaled NO did not change the time course or magnitude of changes in Ppa, Pla, or CO during exercise (Table IV, Fig. 4).

Acute hypoxia caused an increase in Ppa from $19.5 \pm 0.9$ to

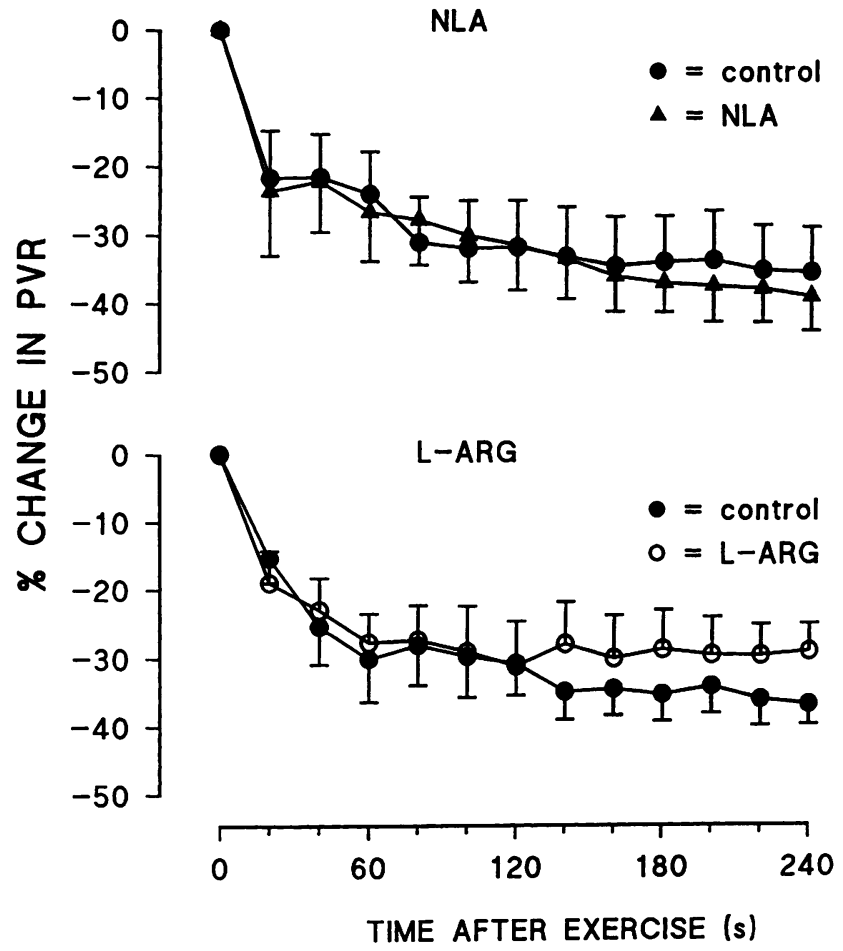

Figure 3. The percent change in PVR after onset of exercise in sheep pretreated with NLA ( $n=6$, paired) and L-arginine $(L-A R G)(n=4$, paired). Values are means \pm SE.

26.4 $\pm 0.7 \mathrm{cmH}_{2} \mathrm{O}$ and an increase in PVR from $4.7 \pm 0.3$ to $5.8 \pm 0.3 \mathrm{cmH}_{2} \mathrm{O} /$ liter per minute (Table IV). During hypoxic exercise, Ppa continued to rise to a peak of $30.1 \pm 2.0 \mathrm{cmH}_{2} \mathrm{O}$ at $40 \mathrm{~s}$ of exercise. After the start of hypoxic exercise, PVR decreased rapidly to a new level that was higher than controls, indicating continued hypoxic vasoconstriction. Inhaled NO fully reversed hypoxia-induced pulmonary hypertension to normal levels at rest and during exercise. In this experiment, $\mathrm{PaO}_{2}$ decreased from $84.2 \pm 3.4$ to $36.1 \pm 1.2$ Torr during hypoxia at rest and to $32.5 \pm 1.7$ Torr during exercise. These levels were unchanged by NO inhalation.

Continuous infusion of U46619 caused significant increases in Ppa and PVR at rest. After the start of exercise, Ppa increased further to a peak of $29.6 \pm 1.9 \mathrm{cmH}_{2} \mathrm{O}$ at $40 \mathrm{~s}$ of exercise. Inhaled NO fully reversed pulmonary hypertension and vasoconstriction induced by $\mathrm{U} 46619$ at rest and during exercise.

In all vasoconstricted groups, the magnitude and time course of percent change in PVR after the onset of exercise were the same as control exercise (Fig. 4). Furthermore, there were no significant effects of inhaled NO on the magnitude and timing of the percent change in PVR after exercise (Fig. 4).

The site of action in NO synthase inhibition and NO inhalation. NLA, hypoxia, and U46619 caused significant increases in Ppa (Figs. 1 and 5). Pmw rose during U46619 infusion (6.8 \pm 0.4 to $10.3 \pm 0.6 \mathrm{cmH}_{2} \mathrm{O}, P<0.05$ ), but not with NLA or hypoxia (Fig. 5). In U46619-treated sheep, PVR significantly increased in both up- and downstream segments, whereas PVR increased mainly in upstream segments with NLA and hypoxia. NO inhalation fully reversed vasoconstriction during hypoxia and $\mathrm{U} 46619$ infusion and resulted in reduction in both up- and downstream resistance during U46619 infusion (Fig. 5). The 
Table III. Systemic Pressure Response at Rest and Exercise to NLA and NLA + L-Arginine

\begin{tabular}{|c|c|c|c|c|c|c|}
\hline & \multicolumn{2}{|c|}{ Rest } & \multicolumn{4}{|c|}{ Exercise $(s)$} \\
\hline & $\mathrm{BL}$ & Treatment & 20 & 60 & 120 & 240 \\
\hline Control & $84.8 \pm 4.9$ & - & $86.6 \pm 3.3$ & $89.2 \pm 4.6$ & $90 \pm 3.9$ & $90.6 \pm 3.7$ \\
\hline NLA & $83.4 \pm 3.1$ & $95.6 \pm 4.5^{*}$ & $95.8 \pm 4.1$ & $98.4 \pm 3.8$ & $99.6 \pm 2.6$ & $102.6 \pm 3.6$ \\
\hline NLA + L-Arginine & $85.4 \pm 3.6$ & $83.6 \pm 2.5$ & $87 \pm 2.7$ & $91.4 \pm 3.1$ & $89.6 \pm 2.5$ & $89.4 \pm 2.9$ \\
\hline
\end{tabular}

Data are means $\pm \operatorname{SEM}(n=5)$ in $\mathrm{mmHg}$ aortic pressure. $* P<0.05$ compared with $\mathrm{BL}$ (base line).

increase in upstream PVR after NLA treatment persisted during exercise. PVRup significantly increased from $3.3 \pm 0.2$ to $7.8 \pm 1.9 \mathrm{cmH}_{2} \mathrm{O} /$ liter per minute after NLA pretreatment at rest and decreased to $4.9 \pm 0.7 \mathrm{cmH}_{2} \mathrm{O} /$ liter per minute at $240 \mathrm{~s}$ of exercise, still higher than in control runs, $2.3 \pm 0.3 \mathrm{cmH}_{2} \mathrm{O} /$ liter per minute $(P<0.05)$ at $240 \mathrm{~s}$ of exercise.

\section{Discussion}

We found that NO synthase inhibition with NLA caused an increase in PVR at rest and during exercise, and the increase in PVR was mainly due to vasoconstriction in vessels upstream from small veins. The hemodynamic effects of NLA were reversed by L-arginine, a substrate for NO synthase. Neither exogenous inhaled NO nor L-arginine caused independent vasodilator effects at baseline or during exercise. We conclude that constitutive NO release contributes to low pulmonary vascular tone at rest and that the effect persists but is not enhanced during exercise.

There has been controversy about the role of NO in the maintenance of normal low resting pulmonary vascular tone. NLA treatment had little effect on the baseline perfusion pres-

Table IV. Effects of NO on Hemodynamics at Rest and Exercise in Preconstricted Vessels

\begin{tabular}{|c|c|c|c|c|c|c|c|c|}
\hline & & \multicolumn{2}{|c|}{ Rest } & \multirow[b]{2}{*}{$\pm \mathrm{NO}$} & \multicolumn{4}{|c|}{ Exercise $(s)$} \\
\hline & & BL & Post-treatment & & 20 & 60 & 120 & 240 \\
\hline \multirow{3}{*}{$\begin{array}{l}\text { Ppa } \\
\quad \text { Control }\end{array}$} & NO & & & & & & & \\
\hline & $(-)$ & $18.5 \pm 0.9$ & $19.4 \pm 1.1$ & & $23.3 \pm 1.6$ & $24.9 \pm 1.6^{*}$ & $24.1 \pm 1.6^{*}$ & $21.8 \pm 1.4$ \\
\hline & $(+)$ & $18.9 \pm 0.7$ & $18.9 \pm 0.7$ & $16.3 \pm 0.8$ & $19.5 \pm 1.0$ & $20.5 \pm 1.4$ & $19.8 \pm 1.4$ & $17.9 \pm 1.4$ \\
\hline \multirow[t]{2}{*}{ Hypoxia } & $(-)$ & $19.5 \pm 0.9$ & $26.4 \pm 0.7^{\ddagger}$ & & $29.7 \pm 1.8^{\ddagger}$ & $29.7 \pm 2.3^{\ddagger}$ & $27.8 \pm 1.8^{\ddagger}$ & $26.8 \pm 1.8^{\ddagger}$ \\
\hline & $(+)$ & $19.3 \pm 0.6$ & $27.7 \pm 0.9^{\ddagger}$ & $18.9 \pm 1.1^{\S}$ & $22.4 \pm 2.3^{\S}$ & $22.3 \pm 2.9^{\S}$ & $20.9 \pm 2.9$ & $20.3 \pm 3.1$ \\
\hline \multirow[t]{2}{*}{ U46619 } & $(-)$ & $17.1 \pm 0.9$ & $26.2 \pm 0.7^{\ddagger}$ & & $28.9 \pm 1.6^{\ddagger}$ & $29.3 \pm 1.9^{\ddagger}$ & $29.5 \pm 1.8^{\ddagger}$ & $26.8 \pm 1.9^{\ddagger}$ \\
\hline & $(+)$ & $17.9 \pm 0.9$ & $29.0 \pm 0.7^{\ddagger}$ & $18.3 \pm 1.0^{\S}$ & $21.1 \pm 1.6^{8}$ & $20.6 \pm 1.8^{8}$ & $19.6 \pm 1.8^{8}$ & $18.7 \pm 2.0^{\S}$ \\
\hline \multicolumn{9}{|l|}{$\mathrm{Pla}$} \\
\hline \multirow[t]{2}{*}{ Control } & $(+)$ & $0.2 \pm 0.9$ & $0.2 \pm 0.9$ & & $0.4 \pm 0.9$ & $0.7 \pm 1.1$ & $0.1 \pm 1.2$ & $-2.0 \pm 1.2$ \\
\hline & $(+)$ & $0.9 \pm 1.0$ & $0.9 \pm 1.0$ & $0.7 \pm 1.0$ & $1.2 \pm 1.1$ & $0.3 \pm 1.4$ & $-0.5 \pm 1.4$ & $-1.4 \pm 1.5$ \\
\hline \multirow[t]{2}{*}{ Hypoxia } & $(-)$ & $-0.2 \pm 0.8$ & $-1.7 \pm 1.1$ & & $0.7 \pm 0.9$ & $-0.3 \pm 1.0$ & $-0.9 \pm 1.1$ & $-1.7 \pm 0.9$ \\
\hline & $(+)$ & $-0.2 \pm 0.7$ & $-0.8 \pm 1.0$ & $-0.6 \pm 1.2$ & $0.8 \pm 0.9$ & $-0.2 \pm 1.4$ & $-0.7 \pm 1.2$ & $-1.5 \pm 1.2$ \\
\hline \multirow[t]{2}{*}{ H46619 } & $(-)$ & $0.7 \pm 0.4$ & $0.9 \pm 0.6$ & & $2.1 \pm 1.1$ & $-0.5 \pm 0.9$ & $-0.5 \pm 1.0$ & $-1.6 \pm 0.8$ \\
\hline & $(+)$ & $1.0 \pm 0.4$ & $2.4 \pm 0.8$ & $1.2 \pm 1.1$ & $1.7 \pm 1.2$ & $0.5 \pm 1.2$ & $0.4 \pm 1.1$ & $-1.2 \pm 0.8$ \\
\hline \multicolumn{9}{|l|}{$\mathrm{CO}$} \\
\hline \multirow[t]{2}{*}{ Control } & $(-)$ & $4.0 \pm 0.3$ & $4.1 \pm 0.3$ & & $6.6 \pm 0.3 *$ & $7.5 \pm 0.4^{*}$ & $7.6 \pm 0.4^{*}$ & $7.5 \pm 0.4 *$ \\
\hline & $(+)$ & $3.9 \pm 0.2$ & $3.9 \pm 0.2$ & $3.9 \pm 0.2$ & $6.3 \pm 0.3 *$ & $7.3 \pm 0.5 *$ & $7.3 \pm 0.5 *$ & $7.2 \pm 0.3 *$ \\
\hline \multirow[t]{2}{*}{ Hypoxia } & $(-)$ & $4.2 \pm 0.2$ & $4.9 \pm 0.2$ & & $6.8 \pm 0.8^{*}$ & $7.6 \pm 0.3^{*}$ & $7.6 \pm 0.2 *$ & $8.0 \pm 0.5 *$ \\
\hline & $(+)$ & $4.1 \pm 0.1$ & $4.9 \pm 0.2$ & $4.8 \pm 0.3$ & $6.7 \pm 0.4^{*}$ & $7.5 \pm 0.4 *$ & $7.5 \pm 0.4 *$ & $7.7 \pm 0.4 *$ \\
\hline \multirow[t]{2}{*}{ U46619 } & $(-)$ & $4.1 \pm 0.2$ & $3.9 \pm 0.2$ & & $6.2 \pm 0.5^{*}$ & $6.7 \pm 0.5^{*}$ & $6.6 \pm 0.6^{*}$ & $6.5 \pm 0.5 *$ \\
\hline & $(+)$ & $3.7 \pm 0.3$ & $3.5 \pm 0.3$ & $3.6 \pm 0.3$ & $5.6 \pm 0.6^{*}$ & $6.0 \pm 0.6^{*}$ & $6.0 \pm 0.5^{*}$ & $6.0 \pm 0.6 *$ \\
\hline \multicolumn{9}{|l|}{ PVR } \\
\hline \multirow[t]{2}{*}{ Control } & $(-)$ & $4.6 \pm 0.3$ & $4.6 \pm 0.3$ & & $3.5 \pm 0.3^{*}$ & $3.2 \pm 0.2 *$ & $3.1 \pm 0.3^{*}$ & $3.1 \pm 0.3 *$ \\
\hline & $(+)$ & $4.6 \pm 0.2$ & $4.6 \pm 0.2$ & $4.0 \pm 0.2$ & $2.9 \pm 0.2^{*}$ & $2.7 \pm 0.2^{*}$ & $2.8 \pm 0.3^{*}$ & $2.7 \pm 0.3^{*}$ \\
\hline \multirow[t]{2}{*}{ Hypoxia } & $(-)$ & $4.7 \pm 0.3$ & $5.8 \pm 0.3^{\ddagger}$ & & $4.3 \pm 0.2^{\tau}$ & $3.9 \pm 0.2^{r}$ & $3.7 \pm 0.2 *$ & $3.6 \pm 0.2 *$ \\
\hline & $(+)$ & $4.8 \pm 0.2$ & $5.8 \pm 0.3^{\ddagger}$ & $4.1 \pm 0.3^{\S}$ & $3.2 \pm 0.2^{* \S}$ & $3.0 \pm 0.2^{* 8}$ & $2.8 \pm 0.3^{* \S}$ & $2.8 \pm 0.3^{*}$ \\
\hline \multirow[t]{2}{*}{ U46619 } & $(-)$ & $4.1 \pm 0.3$ & $6.7 \pm 0.6^{\ddagger}$ & & $4.5 \pm 0.5^{\tau}$ & $4.6 \pm 0.4^{\tau}$ & $4.7 \pm 0.4^{\tau}$ & $4.4 \pm 0.3^{\tau}$ \\
\hline & $(+)$ & $4.3 \pm 0.4$ & $7.3 \pm 0.6^{\ddagger}$ & $4.5 \pm 0.5^{\S}$ & $3.4 \pm 0.4^{\tau}$ & $3.2 \pm 0.4^{\tau \S}$ & $3.1 \pm 0.3^{\tau \S}$ & $3.2 \pm 0.3^{\tau \S}$ \\
\hline
\end{tabular}

*, versus BL (base line) and post-treatment; ${ }^{\S}$, versus without NO. ${ }^{\tau}$, versus time $0 .{ }^{\ddagger}$, versus BL. 


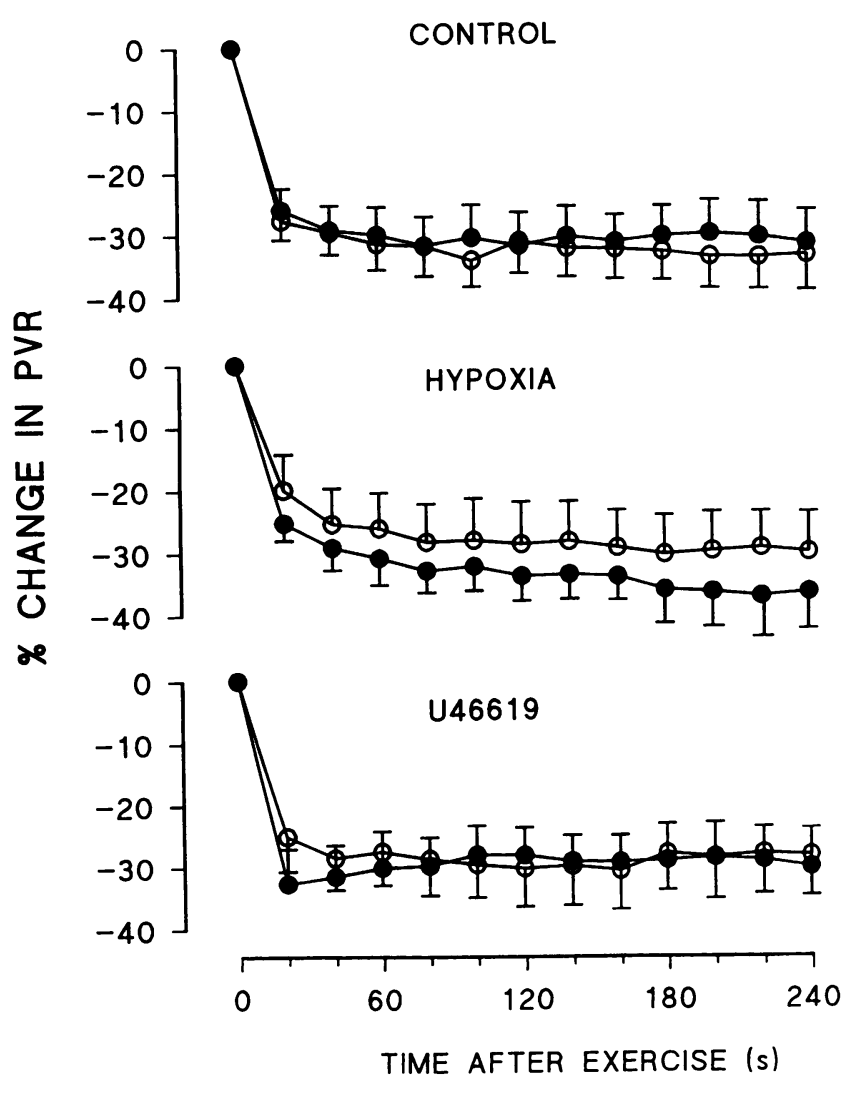

Figure 4. The percent changes in PVR after onset of exercise in controls, with hypoxia and U46619 infusion, with (open circles) and without (filled circles) NO inhalation ( $n=6$, paired for each group). Values are means \pm SE.

sure in lungs of normal rats, but did have an effect in lungs of hypertensive rats (22). Increases in pulmonary vascular tone after treatment with NLA were demonstrated in newborn lambs (19), in the intact cat (23), ovine fetus (13), and hypoxic rabbit (24). In conscious dogs, NO synthase inhibition had no effect on the baseline pulmonary vascular pressure-flow relationship (20). These conflicting results probably reflect species differences and experimental conditions. Our experiments in awake, intact animals may accurately represent the effect of endogenous NO in the pulmonary circulation of normal adult sheep.

We and others have used the microwedge technique to determine the longitudinal distribution of vascular resistance in the pulmonary circulation. The technique allows detection of pulmonary venoconstriction $(6,17,18)$. We found that NO synthase inhibition resulted in a rise in Ppa at rest and during exercise, but did not change Pla or Pmw. Thus, the major site of endogenous NO dilation is in vessels upstream from pulmonary veins of $\sim 2.3 \mathrm{~mm}$ in diameter, the diameter of the Swan-Ganz catheter. This was true both at rest and exercise.

Both pulmonary artery and vein exhibit endothelium-dependent relaxation in response to several endothelium-dependent vasodilators in vitro $(15,16)$. Relaxation in artery and vein were associated with cyclic GMP accumulation (15). Although arterial relaxation was induced by acetylcholine, venous relaxation was elicited by bradykinin but not acetylcholine (15).
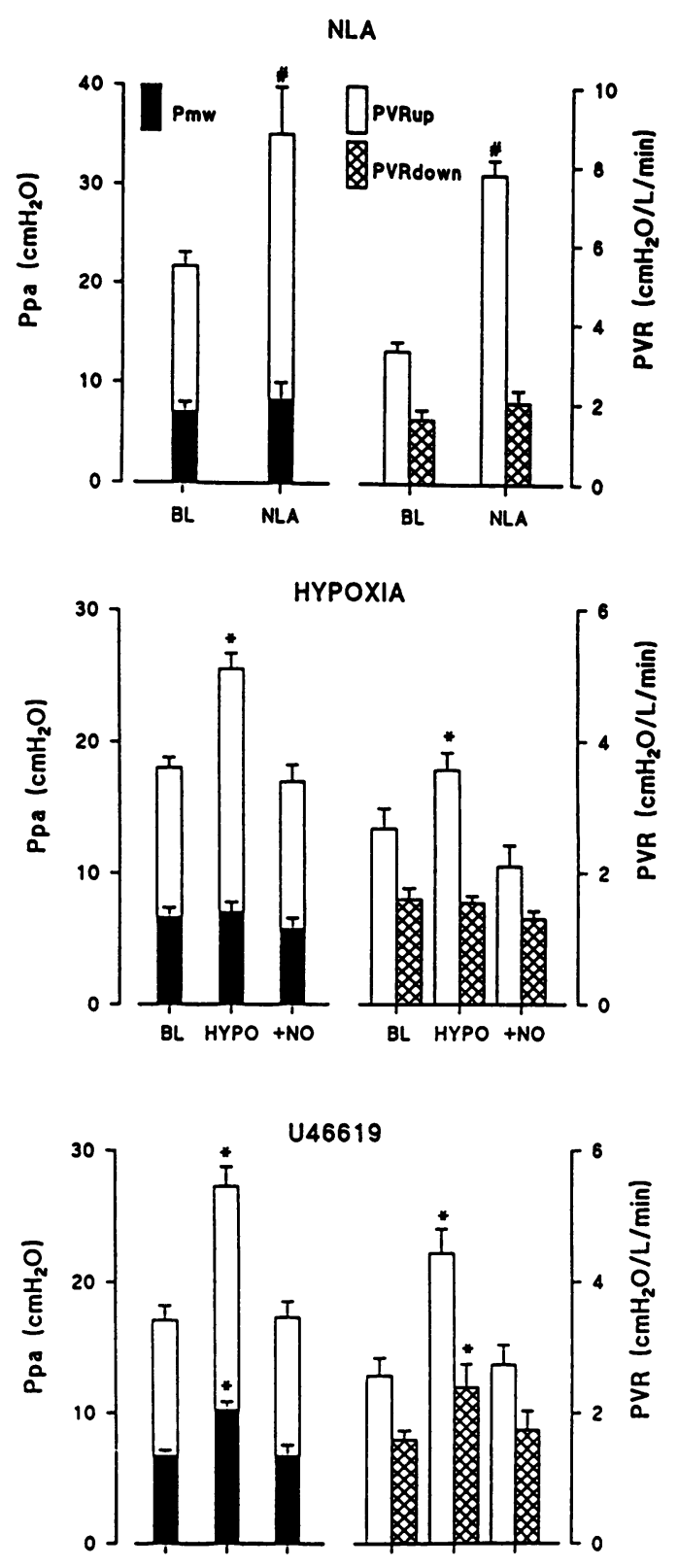

Figure 5. Upstream and downstream Ppa and PVR with NO synthase inhibition (NLA) and NO inhalation at rest. $B L$, baseline; $H Y P O$, hypoxia. Values are means \pm SE. ${ }^{*} P<0.05$ versus baseline. $\mathrm{FIO}_{2}=0.12$. ${ }^{*} P<0.05$ versus other groups.

The physiologic meaning of these different responses to endothelium-dependent vasodilators remains to be elucidated. Our results indicate that at rest the effects of endogenous NO are dominant in small pulmonary vessels, probably arteries. It is not known whether this represents differences in production versus responsiveness to NO in different parts of the pulmonary circulation. Similar findings were made by Cremona et al. (25) using the double vascular occlusion technique. They demonstrated that NLA methyl-ester, another NO synthase inhibitor, caused vasoconstriction in precapillary pulmonary vessels in isolated guinea pig lung.

We were interested in the time course of changes in PVR 
with exercise. PVR decreases rapidly over 0-20 s with the onset of constant rate exercise in normal sheep and then continues to slowly decrease to a lesser extent over several minutes $(2,3$, $6)$. Our prior data (6) and other investigations in humans (4) suggest that the rapid reduction in PVR at onset of exercise is due to recruitment of microvascular bed possessing a low critical opening pressure. Activation of alpha and beta adrenoreceptors occurs in exercise, but these opposing vasoactive effects appear to balance each other $(3,6)$. In the present study, pulmonary vasoconstriction in NLA-treated sheep persisted during exercise compared with control sheep. However, PVR in NLAtreated sheep decreased at the same rate and magnitude as in controls from the new postinhibition baseline. These data suggest that enhanced NO release or effect was not responsible for the reduction in PVR observed in exercise in normal sheep. In addition, pulmonary hemodynamic changes during exercise were not affected by exogenous L-arginine supplement or inhaled NO. Because L-arginine reversed the pulmonary hypertension that resulted from the competitive inhibition of NO synthase and because inhaled NO is clearly an effective pulmonary vasodilator, it is possible that additional NO production does not occur during exercise, or, if NO is increased, that the pulmonary vasculature is already maximally dilated during exercise by flow-related pressure effects (4).

NO may play an important role in the vasodilation response to the increase in blood flow in the newborn. Cornfield et al. (13) reported that in the birth-related increase in pulmonary blood flow in lambs, NLA treatment significantly inhibited both the rise in pulmonary blood flow and the decrease in PVR, supporting the hypothesis that an abrupt increase in pulmonary blood flow stimulated the NO formation in the fetal lung. Differences related to age, oxygenation, and other physiological stimuli between exercise- and birth-related increases in blood flow may account for the differences between our studies.

Hormonal vasoregulation during exercise has not been fully proven. Lindenfeld et al. (26) in dogs and others in sheep (5) have shown previously that prostacyclin does not modulate exercise-induced pulmonary vasodilation, although prostacyclin release is stimulated by shear stress across endothelial cells ( 7 , $10)$. We also previously found that thromboxane formation is not induced during exercise (5). On the other hand, there is a large increase in alpha adrenoreceptor activation during exercise, which is balanced by beta adrenoreceptor-induced vasodilation (6). The effects of NO at rest persist during exercise but are not augmented.

Loss of NO-like activity has been hypothesized to augment pulmonary hypertension in chronic obstructive pulmonary disease (27). Abnormal increases in Ppa and PVR during exercise have been observed in some patients with chronic obstructive pulmonary disease (28). NO activity is impaired in pulmonary arteries from some patients with severe chronic obstructive pulmonary disease, although inhaled NO may reduce Ppa and improve gas exchange in others (27). It is not known whether or not disorders of the release and effect of NO contribute to this abnormal exercise response. Chronic exposure of rats to hypoxia has yielded variable data about endogenous NO, and it is not clear yet whether abnormalities in NO production or response contribute to the observed pulmonary hypertension $(22,29-$ 31 ). Further studies in animal models of human disease and in humans may provide greater insight into the contribution of NO to the pulmonary circulation in health and disease.
In summary, our findings suggest that basal release of endogenous NO plays an important role in maintaining low pulmonary vascular tone at rest and exercise in sheep, but enhanced NO formation is not responsible for the reduction in PVR during exercise. Furthermore, endogenous NO exerts its vasodilator action mainly in small veins or arterioles. Finally, increased lung vascular pressure probably has a dominant role in the reduction in PVR seen during exercise.

\section{Acknowledgments}

This study was supported by National Institutes of Health, National Heart, Lung and Blood Institute grants 45107 and 19153 and the St. Thomas Foundation.

\section{References}

1. Newman, J. H., B. J. Butka, R. C. Parker, and R. Roselli. 1988. Effect of progressive exercise on lung fluid balance in sheep. J. Appl. Physiol. 64:21252131 .

2. Newman, J. H., C. P. Cochran, R. J. Roselli, R. E. Parker, and L. S. King. 1993. Pressure and flow changes in the pulmonary circulation in exercising sheep, evidence for elevated microvascular pressure. Am. Rev. Respir. Dis. 147:921 927.

3. Kane, D. W., T. A. Tesauro, and J. H. Newman. 1993. Adrenergic modulation of pulmonary hemodynamics during strenuous exercise in sheep. Am. Rev. Respir. Dis. 147:1233-1238.

4. Reeves, J. T., J. A. Dempsey, and R. F. Grover. 1989. Pulmonary circulation during exercise. In Pulmonary Vascular Physiology and Pathophysiology, Vol 38, Lung Biology in Health and Disease. E. K. Weir and J. T. Reeves, editors. Marcel Dekker, Inc., New York. 107-133.

5. Newman, J. H., B. J. Butka, and K. L. Brigham. 1986. TxA2 and PGI2 do not modulate pulmonary hemodynamics during maximal or hypoxic exercise in sheep. J. Appl. Physiol. 61:1706-1711.

6. Kane, D. W., T. Tesauro, T. Koizumi, R. Gupta, and J. H. Newman. 1994. Exercise-induced pulmonary vasoconstriction during combined blockade of nitric oxide synthase and beta adrenergic receptors. J. Clin. Invest. 93:677-683.

7. Van Grondelle, A., G. S. Worthen, D. Ellis, M. M. Mathias, R. C. Murphy, R. J. Strife, J. T. Reeves, and N. F. Voelkel. 1981. Altering hydrodynamic variables influences PGI2 production by isolated lungs and endothelial cells. J. Appl. Physiol. 57:388-395.

8. Frangos, J. A., S. G. Eskin, L. V. McIntire, and C. L. Ives. 1985. Flow effects on prostacyclin production by cultured human endothelial cells. Science (Wash. DC). 227:1477-1479.

9. Buga, G. M., M. E. Gold, J. M. Fukuto, and L. J. Ignarro. 1991. Shear stress-induced release of nitric oxide from endothelial cells grown on beads. Hypertension (Dallas). 17:187-193.

10. Rubanyi, G. M., J. C. Romero, and P. M. Vanhoutte. 1986. Flow-induced release of endothelium-derived relaxing factor. Am. J. Physiol. 250:H1145H1149.

11. Palmer, R. M. J., A. G. Ferrige, and S. Moncada. 1988. Nitric oxide accounts for the biological activity of EDRF. Nature (Lond.). 333:664-666.

12. Abman, S. H., B. A. Chatfield, S. L. Hall, and I. F. McMurtry. 1990. Role of endothelium-derived relaxing factor during transition of pulmonary circulation at birth. Am. J. Physiol. 259:H1921-H1927.

13. Cornfield, D. N., B. A. Chatfield, J. A. McQueston, I. F. McMurtry, and S. H. Abman. 1992. Effects of birth-related stimuli on L-arginine-dependent pulmonary vasodilation in ovine fetus. Am. J. Physiol. 262:H1474-H1481

14. Frostell, C., M. D. Fratacci, J. C. Wain, R. Jones, and W. M. Zapol. 1991. Inhaled nitric oxide, a selective pulmonary vasodilator reversing hypoxic pulmonary vasoconstriction. Circulation. 83:2038-2047.

15. Ignarro, L. J., R. E. Byrns, G. M. Buga, and K. S. Wood. 1987. Endothelium-derived relaxing factor from pulmonary artery and vein possesses pharmacologic and chemical properties identical to those of nitric oxide radical. Circ. Res. 61:866-879.

16. Ignarro, L. J., G. M. Buga, and G. Chaudhuri. 1988. EDRF generation and release from perfused bovine pulmonary artery and vein. Eur. J. Pharmacol. 149:79-88.

17. Parker, R. E., and K. L. Brigham. 1987. Effects of endotoxemia on pulmonary vascular resistance in unanesthetized sheep. J. Appl. Physiol. 63:1058-1062.

18. Zidulka, A., and T. S. Hakim. 1985. Wedge pressure in large vs small pulmonary arteries to detect pulmonary venoconstriction. J. Appl. Physiol. 59:1329-1332.

19. Fineman, J. R., M. A. Heymann, and S. J. Soifer. 1991. Nw-nitro-L- 
arginine attenuates endothelium-dependent pulmonary vasodilation in lambs. Am. J. Physiol. 260:H1299-H1306.

20. Nishiwaki, K., D. P. Nyhan, P. Rock, P. Desai, W. Peterson, C. G. Pribble and P. A. Murray. 1992. N $\omega$-nitro-L-arginine and pulmonary vascular pressureflow relationship in conscious dogs. Am. J. Physiol. 262:H1331-H1337.

21. Puybasset, L., T. Stewart, J. J. Rouby, E. Mourgeon, S. Dreux, P. Poete and P. Viars. 1994. Inhaled NO in ARDS: dose response curves. Am. J. Respir Crit. Care Med. 149:A568.

22. Oka, M., K. Hasunuma, S. A. Webb, T. J. Stelzner, D. R. Rodman, and I. F. McMurtry. 1993. EDRF suppresses an unidentified vasoconstrictor mechanism in hypertensive rat lungs. Am. J. Physiol. 264:L587-L597.

23. McMahon, T. J., J. S. Hood, J. A. Bellan, and P. J. Kadowitz. 1991. N $\omega-$ nitro-L-arginine methyl ester selectively inhibits pulmonary vasodilator responses to acetylcholine and bradykinin. J. Appl. Physiol. 71:2026-2031.

24. Sprague, R. S., C. Thiemermann, and J. R. Vane. 1992. Endogenous EDRF opposes hypoxic pulmonary vasoconstriction and supports blood flow to hypoxic alveoli in anesthetized rabbits. Proc. Natl. Acad. Sci. USA. 89:8711-8713.

25. Cremona, G., M. Takano, and J. Higenbottam. 1993. Identification of site of action of nitric oxide in isolated pig lungs by occlusion technique. Am. Rev Respir. Dis. 147:A224.
26. Lindenfeld, J., J. T. Reeves, and L. D. Horwitz. 1983. Low exercise pulmonary resistance is not dependent on vasodilator prostaglandins. J. Appl. Physiol. 55:558-561.

27. Dinh-Xuan, A. T., T. W. Higenbottam, C. A. Clelland, J. Pepke-Zaba, G. Cremona, Y. Butt, S. R. Large, F. C. Wells, and J. Wallwork. 1991. Impairment of endothelium-dependent pulmonary artery relaxation in chronic obstructive lung disease. N. Engl. J. Med. 324:1539-1547.

28. Rogers, T. K., and P. Howard. 1992. Pulmonary hemodynamic and physical training in patients with chronic obstructive pulmonary disease. Chest 101:289-292S.

29. Liu, S., D. E. Crawley, P. J. Barnes, and T. W. Evans. 1991. Endotheliumderived relaxing factor inhibits hypoxic pulmonary vasoconstriction in rats. $A m$. Rev. Respir. Dis. 143:32-37.

30. Adnot, S., B. Raffestin, S. Eddahibi, P. Braquet, and P.-E. Chabrier. 1991. Loss of endothelium-dependent relaxant activity in the pulmonary circulation of rats exposed to chronic hypoxia. J. Clin. Invest. 87:155-162.

31. Russ, R. D., and B. R. Walker. 1993. Maintenance endothelium-dependent pulmonary vasodilation following chronic hypoxia in the rat. J. Appl. Physiol. 74:339-394. 